San Antonio Review • WordPress Imports (Pending Organization) - lan: You can use this.

\title{
On Process: Coffee, Vinyl, and Work
}

Published on: Oct 11, 2017

License:Creative Commons Attribution 4.0 International License(CC-BY 4.0). 
by Ryan Boddy

Most of us agree conceptually that process is of key importance to whatever we do. It's a common talking point at management seminars, in motivational scrums away from the cubicles, and it's a fairly typical subject of life-hack blog posts. Yet in our daily lives we don't often apply principles of process efficiency, or think much about the value of, and the ultimate "why" of doing things the way we do. Hopefully we're doing those things the right way by nature, but I'd bet quite often that we're not. Thing is, I find that examining my more mundane processes translates to how I do daily work in my professional life. If I think of the rituals I perform for things as simple as coffee and transmit that to my thinking about work, my end products are always better. I try to have a reason for doing things the way I do. I want to be able to explain the specificities of my routine so others can apply it to their own if they want.

So what's a real world example of my process analysis? Story time!

My wife and I like to get up on Sunday mornings, have a cup of coffee, eat breakfast - sometimes simple, sometimes big, and listen to a few records. We always start with the Velvet Underground and Nico's selftitled, first release as it literally starts with the song "Sunday Morning." This is in itself a process within the larger, generally less structured, more chaotic process of our week. And within that routine, there are 
yet more processes within processes - making breakfast, cleaning the vinyl before putting on the record, and making coffee.

Here's the part where I kind of bag on my wife a bit - apologies in advance, dear; you know I love you!

My routine when I get up first - see, already we're talking about a simple inconsistency in process that has large effects on the result of the whole - is as follows (Totally tl;dr so skip to the bottom if you want):

- Feed Cats - oh wait, process! We'll go down a list level for each dependent process and its steps, and the "why" as below:

- Fill cat dishes with a roughly "two-mouse-sized" portion of dry food to help keep cats from getting too fat - wife overfeeds them

- Put dishes in specific positions distant from each other, one up on a chair, the other on the floor so large, male cat doesn't eat smaller, female cat's food.

- Make coffee

- Put on the kettle

- Empty kettle - wife never does

- Run hot water for 30 seconds-ish so it's doesn't take as long to boil - if I had a filter, that would lead to another process

- Fill kettle to exact and particular level so it doesn't spit water out of the whistle when it boils, but I still have enough hot water to fill a french press and possibly make oatmeal if I'm not making a bigger breakfast

- Position kettle on stove

- Light burner

- Grind coffee - won't go into buying or storing coffee, but those things should be thought of

- Fill the coffee chopper (it is not a grinder, despite what the box may have said) with appropriate amount of beans to achieve desired strength of final product 
- Pulse coffee chopper with short breaks between pulses to avoid burning the beans -I don't have a burr grinder, so I compensate by adding a layer to my process. You can buy me a burr grinder if you want

- Ensure grinds are appropriate coarseness to ensure an easy plunge upon completion of final product

- Let grinds stand in chopper until ready to add to french press

- When kettle whistles, turn off burner

- Set electronic timer or phone for four minutes, do not start

- Zero/temper the press (raise its temperature)

- Pour enough boiling water into clean french press to raise the temperature of the press prior to brewing of coffee - if press isn't clean it gets done while awaiting the boil, and spent grounds/chaff are added to compost.

- Let water stand in press for about a minute, then empty

- If I'm making coffee for a guest, I might also zero the temp of the mugs, but I often skip this step because I don't like my coffee ultra hot

- Pour enough ground coffee into the press to achieve desired strength

- Bloom the coffee

- Pour enough nearly boiling water (temp should have gone down while you zeroed) into the press to soak the grains. They should be floating about a third of the way up the total volume of the press

- Add a scant pinch of salt to the wet grinds

- Stir so that the coffee grounds are fully soaked, and a foam of tan bubbles appears, and the salt is dissolved

- Let stand for approximately 30 seconds

- Finish filling the press

- Stir the grinds again to achieve a similar foam as in the above step

- Put the plunger on the press, but don't depress

- Start the timer

- Add sugar and almond milk to wife's mug

- When time goes off, depress plunger

- Fill wife's cup to appropriate level, stir to dissolve sugar and diffuse milk

- Fill own cup to appropriate level, add no milk or sugar 
- Deliver coffee to wife in upstairs bedroom, avoid sloshing coffee on the stairs, especially if also carrying own coffee

- Put on Sunday Morning ritual record

- Pull Velvet Underground and Nico from the bookshelf where it's stored, if it's not in its appropriate alphabetical location by band name, and chronological release order by album (this means wife put it away last), hunt for it

- Inspect vinyl; if dirty/dusty clean

- Get out Disc Washer from the shelf beneath the tuner/turntable

- Apply liquid cleaner to the disc as stated in the directions

- Turn on turntable

- Put tone arm in the up position, then move tone arm into position so the platter spins

- Put cleaner brush on the vinyl with the arrow on it pointing in the correct direction

- Put tone arm back in "off" position so the disc stops revolving

- Inspect vinyl for cleanliness, repeat process if necessary

- Flip record, and repeat above process

- Ensure record is on side "a"

- Put away Disc Washer

- Turn on receiver, ensure "phono" is selected as input

- Put tone arm in "up" position

- Put needle in correct position to start the side

- Put tone arm in "down" position

- Make breakfast...

You get the picture. This sounds obsessive, but each of these little steps is fairly simple and doesn't really add that much time to my morning. I enjoy the act of following this process as much as I do the end result. It's a craft I take pride in, just like when I'm brewing beer, making dinner, or writing a post for a blog. It's an examined process. I know exactly why I'm doing the things I'm doing, and I can tell you why - even if it's only about preference, as in how I like black coffee, no sugar, or that I 
don't want my coffee super hot, or that I want to make sure my cats don't get fat.

My wife doesn't make "bad" coffee per sé-it's just not as good as when I make it because I'm taking the time to do it well despite it just being coffee. (Aside: I always think about the scene in Pulp Fiction where Tarantino talks about how his wife buys shit when my wife makes coffee. I know, I am a jerk.) My listening enjoyment of VU and Nico isn't necessarily ruined because of surface noise caused by dirty vinyl when my wife puts on the record, but it sounds a lot better when the disc is clean and there isn't as much surface noise.

It's not that she doesn't care about the quality of the things mentioned above as much as it is that she's just thinking about a final resultbeing caffeinated and hearing a record-she's not a morning person. But when I'm making coffee and putting on a record, she gets awesome coffee and the best sound the equipment can provide. Don't get me wrong, she's professional, and far more obsessive about the things she's very concerned with - like her artwork, or the state of tidiness of our house. I tease her about coffee and her cooking, but as a result she almost never cooks or makes me coffee. (-)

To me, the Sunday morning routine is a ritual that requires reverence. It's like preparing communion at the altar in church except totally heathenish (because I'm at home and my communion is coffee and music about heroin), and the resultant product is noticeably better if 
you take your time, focus on the reasons why each step is there, avoid skipping them, and then appreciate and evaluate the result of that process. But the real deal is what comes after the process is finishedrefinement.

I ask myself if I can taste the coffee the way I want. Was it a little weak, or strong? Could I have added too much salt in that pinch? Was the grind right, or was it difficult to push that plunger? And was there some lint on the first half of "I'm Waiting for the Man" when I finally sat down to sip my coffee and read the news?

I do the same when I think about how I set up an email for a campaign push. Did I ensure I ticked the box to add Google Analytics tracking to the send in Mailchimp? Was the subject line well thought out? And then I look at the reports and think about how I can improve my process to get more responses from the emails I send.

I make rituals of the processes I know work so I can repeat that process and try to better ensure success. Unlike religious rituals, the important thing is not to make process dogmatic. You should always be trying to find better ways to make awesome coffee, just like you should always be willing to examine new data on your process, and new ideas that might increase the chance of success.

Always examine your process because the little things absolutely DO add up to the whole. That said, I sure do wish my wife would make the coffee more often and let me sleep in. 
Originally published at ryanboddy.com on September 28, 2015.

Ryan Boddy is a writer in Baltimore. 